\title{
El complejo Pseudallescheria/Scedosporium y taxas afines en la rutina del laboratorio micológico clínico
}

\author{
(The Pseudallescheria/Scedoporium complex and related taxa in the routine of clinic mycological \\ laboratory)
}

Eduardo Piontelli L *. Universidad de Valparaíso, Escuela de Medicina, Cátedra de Micología. Casilla 92 V, Valparaíso Chile.

*Autor para correspondencia: eduardopiontelli@hotmail.com

Recibido:26-12-12

Aprobado:02-01-13

Palabras Clave: Pseudallescheria/Scedosporium complex, taxa relacionados.

Key words: Pseudallescheria/Scedosporium complex, related taxa.

\section{RESUMEN}

El complejo Pseudallescheria/Scedosporium y taxas relacionados, pertenecientes a un grupo de microhongos con conidios viscosos e integrantes del orden Microascales, se presentan en diversos ambientes comunes asociados a las actividades humanas, ya sea en el suelo como en aguas contaminadas. Actualmente se consideran entre los mayores grupos de hongos filamentosos oportunistas causante de infecciones cutáneas y profundas en el hombre y otros mamíferos. El objetivo principal de este trabajo, consiste en reunir los datos primarios morfofisiológicos más relevantes, útiles para el micólogo médico en el laboratorio, con el aporte adicional de algunos aspectos, biológicos, ecológicos, taxonómicos y moleculares complementarios descritos en la literatura moderna.

\section{INTRODUCCIÓN}

El complejo Pseudallescheria/Scedosporium apiospermum, integra a un grupo de hongos oportunistas ambientales emergentes y relevantes, causantes de un amplio rango de micosis clínicas superficiales y diseminadas ya sea en pacientes con compromiso inmune y ocasionalmente en inmunocompetentes. Estas infecciones comunes en todo el mundo, tienen un relativo alto grado de virulencia que puede deducirse por su infrecuente ocurrencia de sus especies en el aire, pero su alta prevalencia en los pulmones de pacientes suceptibles, en especial en pacientes con fibrosis quística, así como por presentar un alto nivel de resistencia a los antifúngicos (Guarro et al., 2006; Cortez et al., 2008; Lackner et al., 2011a-b). En este último decenio, los integrantes de este complejo y géneros afines se han diversificado como entidades taxonómicas, difiriendo en su ecología y en la habilidad de causar infecciones en humanos y animales, situación que debe ser reconocida y diagnosticada por el micólogo médico (Gilgado et al.,2005-2008-2010; Kaltseis et al., 2009; Eggertsberger et al., 2010). Un limitado número de

\section{ABSTRACT}

The Pseudallescheria/Scedosporium complex and their related taxa are a group of fungus that conidia are presents in viscous mass and belong to the order Microascales. They are in several common enviroment related to human activities either in soil as in contaminated water. Nowadays they are considerated one of the most opportunistic group of filamentous fungus that may cause superficial and deep skin mycoses infections in man and other mammalian. The aim of this work is to gather the primary relevant morphophysiological aspects, usefull to the medical mycologist in the laboratory, plus the contribution of some of biological, ecological, taxonomical and moleculars complementary aspects that are describe in modern literature.

taxas (generalmente 405 ) se presentan comúnmente en los diferentes cuadros clínicos de la literatura internacional, lo que permite en cierta medida, diferenciarlos morfológicamente con la ayuda de algunos datos fisiológicos, una situación de gran ayuda en los hospitales que no poseen en su rutina las técnicas moleculares (Gilgado et al., 2008; Perdomo, 2011). En la actualidad, Pseudallescheria boydii se ha subdividido en numerosas especies, varias de las cuales son prácticamente indistinguibles por caracteres fenotípicos en uso. Un factor complicado consiste en los diferentes grados de entrecruzamiento y clonalidad entre las especies, lo que complica que estas entidades genealógicas pueden referirse como a especies en el sentido clásico. Sin embargo, aceptamos en un amplio consenso que Pseudallescheria es un complejo de especies y no una única especie (Perdomo, 2011; de Hoog et al., 2011).

Debido a lo disperso de la información científica relacionada con este complejo, el objetivo principal de esta presentación, es reunir los datos fenéticos más relevantes útiles para el micólogo en el laboratorio, con el aporte adicional de algunos aspectos,biológicos, 
El complejo Pseudallescheria/Scedosporium y taxas afines en la rutina del laboratorio micológico clínico - E.Piontelli.

ecológicos, taxonómicos y moleculares complementarios descritos en la literatura moderna.

\section{Aspectos bioecológicos. \\ Elcomplejo Pseudallescheria/Scedosporium} (Pezizomycotina, Microascales, Microascaceae), es conocido desde el siglo 19 por sus infecciones poco comunes en humanos, sin embargo, en nuestros días se le considera entre los grupos de oportunistas frecuentes en climas temperados y más esporádicos en los trópicos (Cortéz et al., 2008). No se conoce claramente su nicho natural, sin embargo, los ambientes donde se ha aislado, presentan una fuerte influencia asociada a la actividad humana (Guarro et al., 2006; Kaltseis et al.,2009a). Se encuentra comunmente en el suelo (Ajello ,1952; Cortez et al, 2008; Harun et al.,2009a), en especial en suelos enriquecidos o contaminados, tales como suelos agricolas 0 de jardines (Bakerspigel \& Schaus, 1984), alcantarillas (Cooke \& Kahler,1955), cunetas con barro, ambientes osmóticos, como aguas marinas de estuarios, suelos marinos y madera sumergida en estuarios. así como en diferentes tipos de guano (Kirk,1967; Dabrova et al.,1964), como también en suelos con hidrocarburos donde pueden asimilar gas naturas y compuestos aromáticos, pudiendo usarse como agentes de bioremediación (Clauben \& Schmidt, 1999). Todos estos ambientes pobremente aireados, permiten que el hongo pueda crecer a baja tensión de oxígeno o en condiciones anaeróbicas y tolerar in vitro $5 \%$ de cloruro de sodio (De Hoog et al.,(1994).

El traslado de los integrantes de este complejo desde un hábitat particular determinado (rurales u otros) a otros diferentes nichos ecológicos naturales poco conocidos, incluyendo los nuevos ambientes dominados por el hombre, puede permitir una selección de genotipos virulentos (cepas clínicas versus ambientales). Esto ofrece una amplia oportunidad para las especies, aumentando muchas de ellas su virulencia sin poner en riesgo su propia existencia. Mientras más rápido crecen los genotipos resistentes, muchas cepas tienen más capacidad de transmisión y selección, quizás en un corto camino evolutivo (De Hoog, 2012).

A pesar de su ocurrencia en los suelos y aguas en climas temperados, el compejo Pseudallescheria/ Scedosporium es consistentemente termotolerante $\left(37-42^{\circ} \mathrm{C}\right)$ con la habilidad de sobrevivencia a muy bajas presiones de oxígeno.(Dabrowa et al., 964; Kaltseis et al., 2009; Eggertsberger, et al., 2010). Esto podría indicar un nicho ecológico asociado a los animales de sangre caliente como vectores de diseminación (http://www.scedosporium-ecmm.com/ DefaultInfo.aspx?Page $=$ Home.....2010).

\section{Importancia clínica.}

Los cuadros clínicos más diversos encontrados en la literatura son comunes en todo el orbe, ya sea en pacientes con compromiso inmmune como en inmunocompetentes: micetoma, artritis, osteomielitis, endoftalmitis u otras infecciones oculares, onicomicosis, sinusitis, otitis, bolas fúngicas pulmonares, broncopatías alérgicas, cuadros graves con infecciones pulmonares invasivas, endocarditis, infecciones del sistema nervioso central, entre otras et al., 2000; Dalton et al., 2006; Guarro et al., 2006; Cortez et al., 2008; Rodriguez-Tudela, et al. (2009). Cortez et al., 2008; Harun et al., 2009b; Gelabert-González et al., 2010). Muchos de estos cuadros clínicos derivan en micosis sistémicas, con altas tasas de mortalidad debido a la elevada virulencia y a la resistencia a los tratamientos antifúngicos convencionales que presenta este grupo de hongos, en especial S.prolificans (AlastrueyIzquierdo, et al., 2007; Cortez et al., 2008, RodriguezTrudela et al., 2009; Lackner et al., 2011). En Chile, se han descrito diversos casos de scedosporiosis, principalmente del complejo Pseudallescheria/ Scedosporium y S. prolificans (Oddo, et al., 1985; Díaz et al., 2004; Briones et al., 2006; Chanqueo et al., 2009, entre otros). Debe destacarse el reciente aislamiento de Psudallescheria boydii sensu stricto, en un paciente con cuadro sinusal (Nota del autor).

Las especies clínicamente más relevantes son:

Pseudallescheria boydii con su anamorfo Scedosporium boydii, Scedosporium apiospermum, anamorfo de Pseudallescheria apiosperma, Scedosporium aurantiacum, Scedosporium prolificans y Scedosporium de hoogii, mientras Pseudallescheria minutispora, Petriellopsis desertorum y algunos integrantes del género Petriella son agentes excepcionales en micosis humanas 0 animales (Issakainen et al. 1997, 1999, de Hoog et al. 2000,0kada et al. 2000; Gilgado et al., 2005- 20082010; Cortez et al., 2008).

\section{Aspectos Taxonómicos.}

El género ha experimentado diversos cambios en su nomenclatura en el tiempo. Saccardo, en 1911, aisló de un paciente con micetoma un hongo al cual denominó Monosporium apiospermum, posteriormente el mismo autor lo denominó Scedosporium, sin proponer formalmente el género. En 1919, Castellani y Chalmers validan el nombre Scedosporium con la nueva combinación, $\boldsymbol{S}$. apiospermum. En 1922, Shear describe un nuevo ascomycete, Allescheria boydii, aislado de un micetoma y Emmons (1944), sugirió que $\boldsymbol{S}$. apiospermum era el anamorfo de $\boldsymbol{A}$. boydii. En 1970, Malloch reclasificó el teleomorfo como Petriellidium boydii, y más tarde esté genero fue considerado sinónimo de Pseudallescheria. Hughes (1958), acepta S.apiospermum como nombre correcto para el anamorfo de $\boldsymbol{P}$. boydii.

Malloch y Salkin(1984), describieron la nueva especie Scedosporium inflatum, aislada de médula 
El complejo Pseudallescheria/Scedosporium y taxas afines en la rutina del laboratorio micológico clínico - E.Piontelli.

ósea en un niño inmunocompetente y Gueho y De Hoog (1991), mediante reasociación ADN/ADN, demostraron que Lomentospora prolificans tenía $100 \%$ de identidad con $\boldsymbol{S}$. inflatum y propusieron la nueva combinación S. prolificans. Más recientemente, a partir de datos genéticos y morfológicos, Gilgado et al. $(2005,2008,2010)$ propusieron nuevas especies ( $\boldsymbol{S}$. aurantiacum, $\boldsymbol{S}$. boydii y $\boldsymbol{S}$.dehoogii, esta última incluye la nueva especie $\boldsymbol{S}$. deficiens (Rainer \& Kaltseis 2010), lo que indica la heterogeneidad de sus integrantes.

\section{Aspectos fenéticos y filogenéticos útiles en el diagnóstico}

Los integrantes del género polimórfico Scedosporium y sus relativos, incluyen anamorfos con conidios húmedos. Graphium y Parascedosporium también pertenecen a este complejo, mientras los teleomorfos se encuentran en Pseudallescheria, Petriella, Petriellopsis y Lophotricus (von Arx y col., 1988; de Hoog y col., 2000; Gilgado et al., 2005, 2007, 2009; Lackner \& de Hoog, 2011).

La biología molecular subdivide en varios clados fisiológicos, genéticos y ecológicos a este grupo de hongos (Lakner et al., 2010; Lackner \& de Hoog, 2011). El clado oportunista Pseudallescheria, se caracteriza por la producción de cuerpos fructíferos cerrados (cleistotecios), esféricos (Fig. 1), con paredes finas, membranáceas y de textura "epidermoidea" (Shear, 1922). Los ascos suelen ser esféricos, de paredes delgadas, evanescentes y contienen gene-

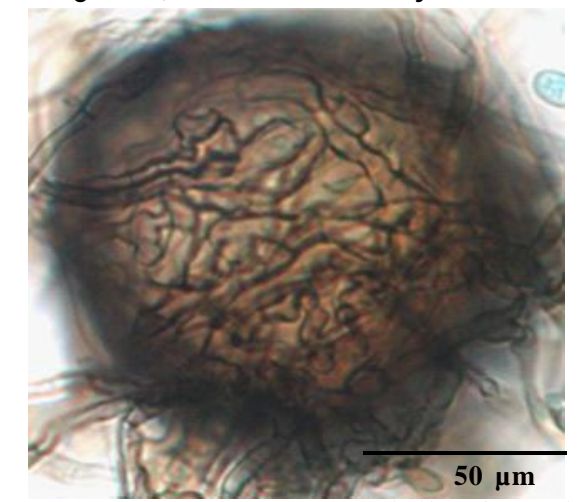

Figura 1- Cleistotecio de Pseudallescheria boydii con sus paredes de textura epidermoidea

ralmente ocho ascosporas usualmente simétricas, elipsoidales o fusiformes. Incluye las sigueintes especies: Scedosporium aurantiacum, Scedosporium dehoogii, Pseudallescheria minutispora, Pseudallesche-ria angusta, Pseudallescheria apiosperma, Pseudal-lescheria desertorum (=Petrellidium desertorum); esta última es otra especies estrechamente relacionada (Lu et al., 2011). Scedosporium (fFg. 2A-B) se caracteriza por presentar conidioforos usualmente no ramificados, con células conidiógenas anelídicas. Las células conidiógenas

Bol. Micol. 2012; 27(2): 65-77
0 anélides pueden presentarse también en forma sésil sobre hifas indiferenciadas, con conidios de forma obovoidal y de color marrón. (Dykstra et al., 1989).

Scedosporium prolificans, integra un clado separado, sin teleomorfo conocido, sin embargo, es también oportunista en el hombre y representa el más cercano relativo a Parascedosporium putredinis

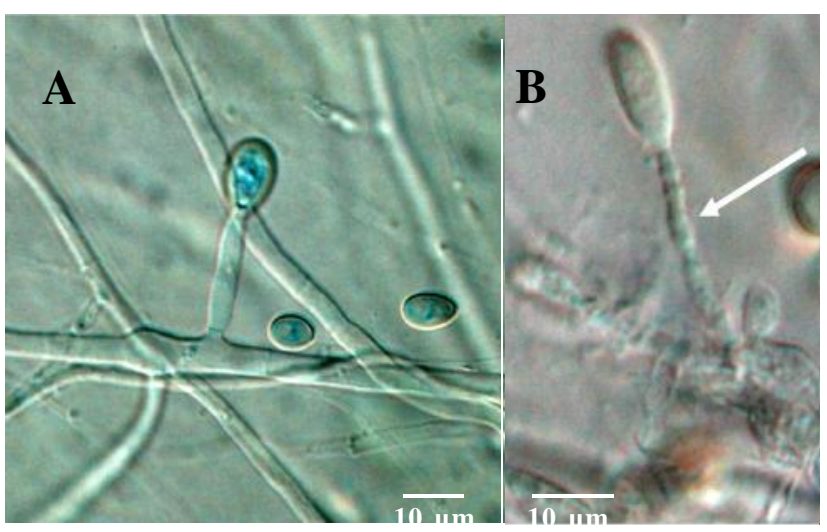

Figura 2. A. Célula conidiògena joven de Scedosporium apiospermum, B. Detalle de anélide en célula conidiógena madura (flecha)

como clado hermano. En contraste con $\boldsymbol{S}$. prolificans, P. putredinis fue reportado solo $1 \mathrm{vez}$ en una infección humana por Vuillemin en 1910, como Rhinocladium lesnei. Sin embargo, se ha dudado de la credibilidad de este caso y no se ha encontrado nuevamente en infecciones humanas (Lackner \& de Hoog, 2011).

Petriella sordida, Petriella guttulata , Petriella setifera y Petrellopsis africana, forman un clado separado asociado al suelo y los excrementos y aparentemente no se han detectado en infecciones humanas.

Gilgado et al. (2007) introducen el género polimórfico Parascedosporium en su revisión de Scedosporium; su descripción fué basada en una cepa auténtica de Graphium tectonae (Booth 1964), CBS 127.84, que renombraron Parascedosporium tectonae, aislado de semillas de Tectonia grandis en Jamaica.

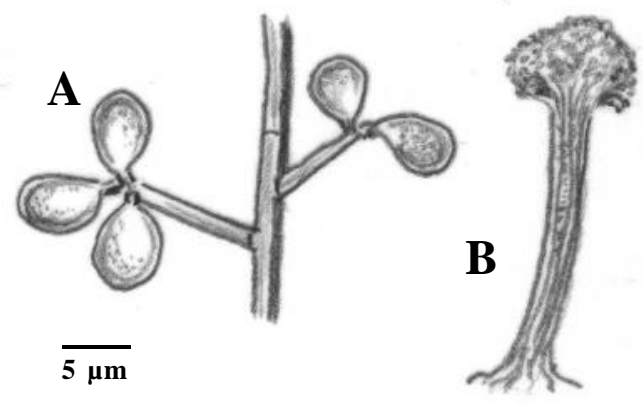

Figura 3. A. Parascedosporium putredinis. Conidios semejantes a scedosporium que nacen lateralmente sobre dentículos. B. Estado de Graphium 
Scedosporium, consistentemente presenta una conidiogénesis percurrente, mientras Parascedosporium presenta una conidiogénesis simpodial con conidios semejantes a scedosporium. Lackner \& de Hoog (2011), investigaron las características morfológicas de varias cepas de G. putredinis y una cepa de Parascedosporium tectonae, obsevando que todos los aislados presentan las caracteríasticas de conidióforos solitarios semejantes a scedosporium, que originan células conidiógenas laterales cilíndricas con 2-5 dentículos cilíndricos, incluso algunas cepas farman sinnemata adicional con conidiogénesis anelídica. Debido a esto concluyen que la nomenclatura de este grupo de especies debe modificarse en una nueva combinación como Parascedosporium putredinis (Vea lista de sinónimos en el trabajo de estos autores). No hay evidencias que el clado $\boldsymbol{P}$. putredinis, puede ser virulento en los humanos, y al parecer no exhibe ninguna especialización ecológica, debido a que sus cepas se han aislado desde material vegetal vivo, suelo, excrementos y detritus vegetales, su temperatura máxima de crecimiento es de 37 C. (Lackner \& de Hoog 2011).

Graphium se caracteriza por presentar conidióforos ramificados, especialmente en el ápice de su sinema de color aceituna-marrón (Fig. 4), que termina en un conjunto apretado de células conidiógenas (anélides) delgadas en cuyo ápice se acumulan los conidios en una masa mucoide. Su conidiogénesis es similar a la de Scedosporium, pero sus células conidiógenas son más pequeñas y los conidios más estrechos y menos pigmentados (de Hoog et al., 2000). Este sinanamorfo no siempre está presente en los cultivos (Vea Tabla 1).

La familia Microascaceae incluye otros géneros que son morfológicamnete similares a Pseudallescheria (von Arx y col., 1988). Entre los que también presentan anamorfos en Scedosporium y Graphium, como el género Petriella Curzi (Fig. 5. A-B),

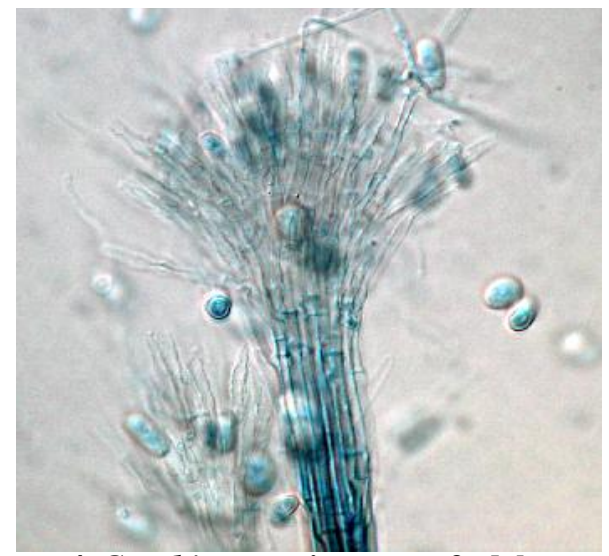

Figura 4. Graphium sp. sinanamorfo del complejo Pseudallescheria/Scedoaporium

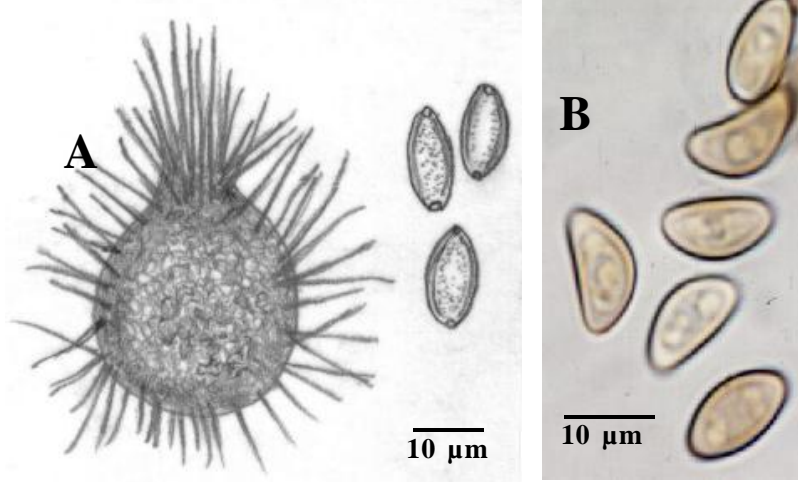

Figura 5. A. Petriella setifera. Peritecio y ascosporas, B. Ascosporas de Petriella guttulata (Tomado de: website.nbm-mnb.ca)

que se distingue principalmente por presentar ascomas ostiolados (peritecios). Von Arx (1973), sugirió que la presencia 0 ausencia de aberturas en los peritecios podría estar influenciada por las condiciones culturales, situación demostrada posteriormente por Issakainen et al., (1997, 1999) y Rainer y de Hoog, 2006) a partir de sus estudios moleculares basados en los genes $18 \mathrm{~S}$ y $28 \mathrm{~S}$ del ADN ribosómico (ADNr). Dichos estudios determinaron que Petriella y Pseudallescheria son géneros genéticamente bien diferenciados.

Aunque son varias las especies de Scedosporium de importancia clínica, sólo las más comunes (4-5) permiten su descripción con aportes morfofisiológicos útiles en la rutuina primaria del laboratorio micológico (Gilgado et al., 2008).

Conocemos que el complejo Pseudallescheria concentra el mayor número de cepas clínicas en la literatura e incluye patógenos ambientales con anamorfos en Scedosporium y Graphium.Varias especies de Pseudallescheria y Scedosporium, se consideran organismos indicadores de contaminación en el suelo y las aguas, mientras que la temperatura y la dependencia de ciertas condiciones ambientales aumentan la distribución de estos oportunistas, en especial del complejo Scedosporium dehoogii, en suelos enriquecidos con hidrocatburos alifáticos (Ulfig et al., 2008; Kaltesis et al., 2009; Eggertsberger, et al., 2010).

La morfología del conidióforo y de los conidios sésiles y la apariencia de las colonias en PDA son las caracteríasticas más útiles para separar fenotipicamente las diferentes especies en los diferentes clados. Ninguno de los aislados que corresponden a $\boldsymbol{S}$. apiospermum y S. dehoggii desarrollan el teleomorfo después de 2 meses, mientras todos ellos desarrollan el anamorfo en Scedosporium. Los conidióforos sinematosos (anamorfo en Graphium ), son usualmente ausentes en S. dehoggii, sin embargo, ellos se presentan en un $90 \%$ en $\boldsymbol{S}$. apiospermum. S.dehooggii, se caracteriza por conidióforos solitarios y usualmente no ramificados, subhialinos a gris pálidos y de paredes finas, conidios 
El complejo Pseudallescheria/Scedosporium y taxas afines en la rutina del laboratorio micológico clínico - E.Piontelli.

sésiles y colonias gris pálido, mientras los miembros

S.apiospermum muestran conidióforos ramificados, y conidios sésiles cafesosos de paredes gruesas y colonias cafesosas (Gilgado et al., 2008). El uso de biodisel permite un mejor aislamiento de $\boldsymbol{S}$. dehoogii y $\boldsymbol{S}$. deficiens, mientras $\boldsymbol{S}$.aurantiacum es común en áreas cálidas y áridas (Rodriguez -Trudela, 2009).

Petriella y Petriellopsis africana, se ailan mayoritariamente de excrementos de herbívoros y suelo, salvo excepciones y parece poco probable su oportunismo en vertebrados (Lackner \& de Hoog, 2011).

Varios casos clinicos en animales, atribuibles a cepas de Graphium,se asocian a cepas posiblemente mal identificadas de Graphium eumorphum, debido a que en los casos que se han podido estudiar molecularmente son similares 0 idénticas a $\boldsymbol{P}$. boydii o P.apiosperma (Lackner \& de Hoog, 2011).

Aquellas especies relacionadas con los Ophiostomatales con una morfología aparente de Graphium, residen en Pesotum, En contraste, Graphium fue redefinido para incluir todas las especies sinematosas en las Microascales, incluyendo las pertenecientes a los complejos $\mathbf{G}$. penicillioides y $\mathbf{G}$. putredinis (Okada et al. 1998, 2000). Los agregados en $\mathbf{G}$. putredinis son filogenéticamente relacionados con las especies de Parascedosporium, Petriella, Pseudallescheria y Scedosporium que son oportunista en humanos (Issakainen et al. 1999, de Hoog et al. 2000, Okada et al. 2000, Gilgado et al. 2007).

Las especies de Graphium, muestran estrecha asociación con los escarabajos de la corteza, salvo un caso clínico de $\mathbf{G}$. basitruncatum en una leucemia (Kunart et al.2007), mientras Parascedosporiun putredinis (=Gra-phium putredinis), parece no exhibir ninguna especialización ecológica (Lackner \& de Hoog (2011).

Es esencial en laboratorio micológico clínico la recuperación de los datos más recientes en la literatura, para el entendimiento del complejo Pseudallescheria/Scedosporium. En 2002, un grupo amplio de investigadores Europeos se asociaron para compartir estudios sobre este grupo de hongos bajo el paragua de la European Confederation of Medical Mycology (ECMM) (www. scedosporiumecmm.com). Una iniciativa similar fue seguida en Australia por The Australian Scedosporium Study Group (AUSCEDO), ambos grupos fueron intena-cionalizados bajo el auspicio de la International Society of Human and Animal Mycology (ISHAM). Los objetivos generales de estos grupos de trabajo son los de obtener un mejor conocimiento en la epidemiología y variabilidad genética de estos hongos, como provever datos de posibles fuentes de contaminación y rutas de infección, así como ofrecer la ayuda necesaria para la identificación molecular de los integrantes de este complejo (De Hoog et al., 2011).

\section{El aporte de las técnicas moleculares}

La taxonomía del complejo se ha modificado drásticamente desde la aplicación de la biología molecular, en particular por los artículos de Gilgado et al. (2005-2008-2010), una situación que permitió subdividir la clásica especie de Pseudallescheria boydii en numerosas especies, varias de las cuales son indistinguibles fenotípicamente con los métodos en uso en la actualidad.

Scedosporium apiospermum fué considerado tradicionalmente el anamorfo de Pseudallescheria boydii, sin embargo, recientes estudios moleculares han demostra-do que son 2 especies difrerentes, debido a que S.apiospermum es una especiea heterotálica y su teleomorfo es Pseudallescheria apiosperma (Gilgado et al., 2008).

Se observa que en los últimos decenios, la literatura presenta una amplia variación de técnicas moleculares para tipificar los aislados del complejo Pseudallescheria/Scedosporium y sus relativos (Issakainen et al.,1997; Gilgado et al., 2005-20082010; Harun et al., 2009b; Lackner et al., 2010; Lackner \& de Hoog, 2011; Lu et al., 20011), las cuales han permitido discriminar entre las cepas, especi-ficar posibles fuentes de infección, grados de virulencia 0 determinar la actividad frente a los antifúngicos (San Millan et al., 1997; Gilgado et al., 2006; Guarro et al., 2006; Delhaes et al., 2008).

Los métodos moleculares más discriminatorios para especies de Scedosporium son: AFLP, RAPD, PCR y PCR de secuencia entre repeticiones simples (ISSR-PCR) (San Millan et al., 1997; Ruiz-Diez et al. 1997; Solé et al., 2003; Delhaes et al., 2008; Lackner et al., 2011-2012). Dichos análisis han mostrado diversos grados de variación genética, incluso en algunos se han obtenido resultados contradictorios por las infuencias de varios factores (diferencias en los métodos y marcadores utilizados, cepas no representativas o el limitado número de aislados estudiados (San Millan et al., 1997; Ruiz-Diez et al. 1997; Solé et al., 2003; Delhaes et al., 2008; Perdomo, 2011). También se ha usado la electroforesis enzimática de multilocus (MLEE) (Zouhair , et al., (2001), así como varios genes como la b-tubulina (Gilgado et al., 2005-2008), la calmodulina (Gilgado et al., 2005), la EF1a (Zeng et al., 2007), los cuales presentan una considerable variabilidad genética. Ultimamente, sumándose a estos métodos se ha empleado un robusto sistema de multilocus Sequence Typing (MLST), que provee un buen método de diferenciación de cepas debido a que los metodos fenotípicos convencionales tienen limitado uso para fines epidemiológicos, por ser inadecuadamente descriminatorios (Harun et al., 2009a). Para el grupo de investigadores Lackner et al, (2010); Lackner \& de Hoog (2011), De Hoog et al., 2011). Las secuencias de ITS, la B tubulina 2 y los locus TBC de la B-tubulina, 
El complejo Pseudallescheria/Scedosporium y taxas afines en la rutina del laboratorio micológico clínico - E.Piontelli.

son suficientes para delimitar las especies del complejo Pseudallescheria/Scedosporium. Recientemente la espectrometría de masa se está imponiendo como otro método confiable y rápido para la identificación de este complejo, así como de otros hongos y bacterias (Krasny et al., 2011; Sitterle et al., 2012), así como el tipiado fisiológico de las cepas mediante el «Taxa Profile MICRONAUT system», un sistema semi automático asistido por computador (Horre et al., 2011).

\section{Diagnóstico de laboratorio}

En la mayoría de los casos el hongo se aisla desde cultivos de esputo, de especímenes quirúrgicos o lavado bronquial. A. fumigatus también puede encontrarse asociado en el pulmón, una situación frecuente y que puede enmascarar el diagnóstico por su crecimiento más rápido que el complejo Pseudallescheria/Scedosporium y es de utilidad un test de precipitinas que reacciona fuertemente con el primer agente y una débil reaccion con A.versicolor. A pesar de, la utilidad del cultivo de esputo y el empleo de inmmunoprecipitinas en el suero a veces es necesario una muestra por extirpación quirúrgica para el diagnóstico. (Bonduel et al., 2001; Kantarcioglua, et al., 2012)

El cultivo en agar papa dextrosa es el medio más empleado para su determinación morfológica, pero no debemos olvidar que las cepas de Scedosporium son de lento crecimiento si e comparan con otros hongos saprófitos oportunistas como los Aspergillus (7 a 10 días versus 2 a 4 días, respectivamente), para producir colonias que esporulan. Esto permite considerar el subdiagnóstico de las especies de Scedosporium en pacientes con fibrosis quística, donde la colonización de los pulmones es concomitante con A. fumigatus (Blyth et al., 2010).

La histopatología muestra hifas con multiples ramificaciones en ángulo agudo o dicotómicas, también suele observarse la presencia de clamidosporas globosas terminales 0 intercalares, de hasta 20 um de diámetro (Fessler \& Brown, 1989; Walts, 2001).

Es recomendable depositar el material vivo obtenido en uno de los centros reconocidos de colección para posteriores estudios (ej. CBS).

\section{Medios de cultivo específicos}

Rainier et al. (2008), desarrollaron un medio semi selectivo para el eislamiento de P.boydii y especies relacionadas despues de $5-7$ días a $36-37^{\circ} \mathrm{C}$, que denominaron Scedosporium selective Agar (SceSel+), cuya composición es la siguiente. Extracto de malta, $6.25 \mathrm{~g}$; maltosa, $6.25 \mathrm{~g}$; monofosfato de potasio, $1.25 \mathrm{~g}$; extracto de levadura, $1.0 \mathrm{~g}$; Sulfato de magnesio $7 \mathrm{H} 20,0.625 \mathrm{~g}$; peptona de soja, 0.625 $\mathrm{g}$; cloramfenicol, $0.1 \mathrm{~g}$ (diluido en $5 \mathrm{ml} \mathrm{d}$ etanol al $96 \%$ ); ciprofloxacino, $0.1 \mathrm{~g}$ (diluido en $1 \mathrm{ml}$ de $\mathrm{NaOH}$ a $1 \mathrm{M}$ y agregado al agar a $55^{\circ} \mathrm{C}$; Sulfato de estreptomicina, $0.1 \mathrm{~g}$ (diluido en $5 \mathrm{ml}$ filtrada en filtro estéril y agragado al agar a $55^{\circ} \mathrm{C}$ ); dichloran, $2 \mathrm{mg}$ (diluido en $1 \mathrm{ml}$ en una solución al 0,2 de etanol); benomy I,6 $\mathrm{mg}$ (diluido en $5 \mathrm{ml}$ de etanol y agregado al agar a $55^{\circ} \mathrm{C}$ ); agar, $20 \mathrm{~g}$; y agregar $983 \mathrm{ml}$.de agua destilada. Si se emplea este medio sin el benomyl (SceSel- ), A. fumigatus no se inhibe y tiene un crecimiento mayor. En este medio el efecto selectivo de nivel de germinación es alto pudiendo llegar a cifras cercanas al $90 \%$, mientras en los medios no selectivos (PDA, SGA y MEA, Ios niveles no sobrepasan el 50\%.

El aislamiento de fuentes ambientales con el medio SceSel+ es muy exitoso, confirmando que el impacto humano en los suelos favorece la frecuencia del complejo Pseudallescheria/Scedosporium. Puede emplearse también el medio agar Rosa de Bengala Cloramfenicol suplementado con benomil a una concentración de $10 \mathrm{ml}$ (Harun et al., 2009a). Debe destacarse que $\boldsymbol{S}$. prolificans difiere de $\boldsymbol{P}$. boydii por su capacidad de crecer en DG18, este medio puede ser usado para su rápida separación cuando no se emplean métodos moleculares (Rainier et al., 2008).

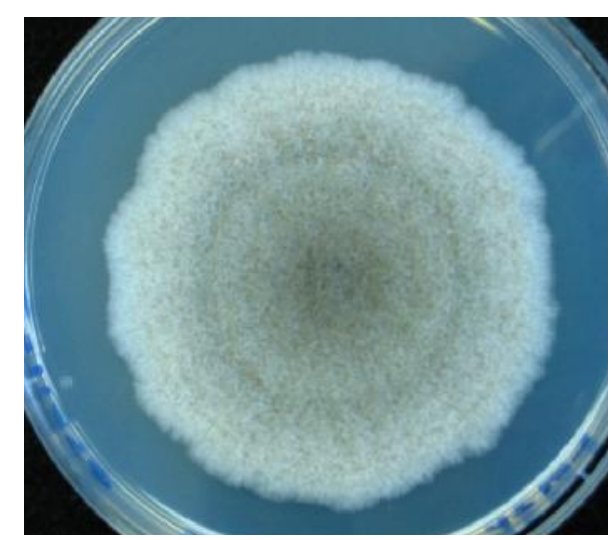

Figura 6. Colonia de Scedosporium apiospermum, en PDA,14 días a $30^{\circ} \mathrm{C}$ (Dea Garcia Heermoso, CNRMA Institut Pasteur, Scedosporium meeting, Bonn, 2010).

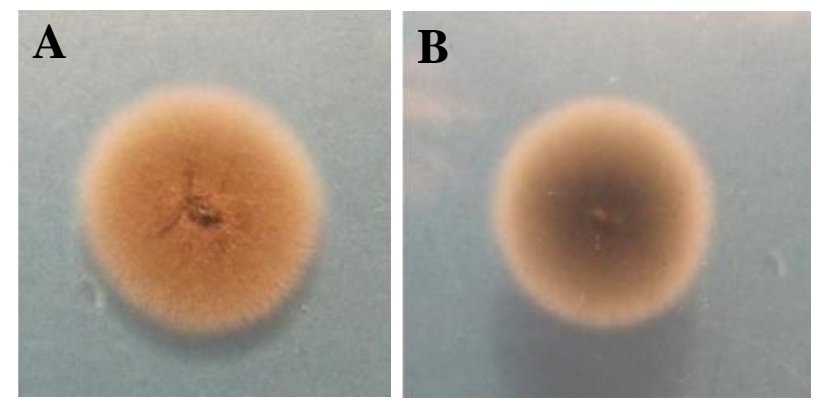

Figura 7. A-B, Colonia de Scedosporium prolificans (Anverso y reverso) en PDA durante 7 días a $30^{\circ} \mathrm{C}$.

Descripción morfofisiológica de algunos taxa comunes en cuadros clínicos diversos 0 aislados desde el ambiente. 
1. Pseudallescheria boydii (Shear)McGinnis, A.A,Padhye \& Ajello Anamorfo Scedosporium boydii (Shear) Gilgado, Gené, Cano et Guarro.

Colonias flocosas o lanosas de crecimiento relativamente rápido, 30$45 \mathrm{~mm}$ en PDA a los 14 días a $25^{\circ} \mathrm{C}$. Ascomata cleistotecial (Figura $8 \mathrm{~A}$ ), inmersos 0 superficiales, 50-200 $\mu \mathrm{m}$ diám., textura epidermoidea, negros, paráfisis ausentes; ascos evanescentes, unitunicados obovoides a redondos, $12-18 \times 9-14 \mu \mathrm{m}$, Ascosporas amarillentas a café claro con un poro germinal en ambos extremos, unicelulares, elipsoidales a fusiformes, lisas, 6-9 x 5-6 $\mu \mathrm{m}(\mathbf{A})$. Anamorfo en Scedosporium con conidios húmedos sobre células conidiógenas anelídicas (percurrentes), en el micelio aéreo, subhialinos a café, subesféricos a elongados, 6-11 x 3,5-6 $\mu \mathrm{m}$ (B), que se tornan café y de paredes gruesas al liberarse. Otros conidios sésiles nacen desde hifas vegetativas, abundantes, esféricos 0 subesféricos 5-7 x 5-6 $\mu \mathrm{m}$ (C). A veces presencia de un sinanamorfo en Graphium con estipe cilíndrico, liso, conidios en células conidiógenas anelídicas, subhialinos 0 café pálidos, reunidos en substancia mucoide, ampliamente clavados 6-12 × 3,5-4 $\mu \mathrm{m}$. Distribución universal. Referencias Gueho \& de Hoog, 1991; De Hoog et al., 2000; Gilgado et al., 2007-2010)

Un pequeño porcentaje de cepas produce espontaneamente ascomas, sin embargo, su formación puede ser estimulada en medios pobres como agar maíz, agar avena o agar papa zanahoria, en 2-3 semanas. P.boydii no crece en agar DG18 (baja actividad de agua) y esto permite diferenciarlo de Scedosporium prolificans que crece en este medio). El patrón de asimilación de $\boldsymbol{P}$. boydii, P.angusta, $\boldsymbol{P}$. ellipsoidea y $\boldsymbol{P}$. fusoidea son similares, sin diferencias significativas. La asimilación de sucrosa, maltosa, D-ribosa, Larabinitol y ribitol, así como el crecimiento a 40 y $45^{\circ} \mathrm{C}$ permite disciminar entre las especies (Gilgado et al., 2005). Vea Tabla 2.

\section{Pseudallescheria apiosperma Gilgado, Gené, Cano et Guarro.} Anamorfo Scedosporium apiospermum (Sacc.) Castellani \& Chalmers

Colonias de crecimiento relativamente rápido, $35-55 \mathrm{~mm}$ en PDA a los 14 días a $25^{\circ} \mathrm{C}$, blancas grisáceas con un reverso gris a negro. Células conidiógenas cilíndricas hialinas que nacen de hifas indiferenciadas unicas 0 ramificadas, que producen numerosos conidios café pálidos, ampliamente clavados a ovoides, 4-9 × 6-10 $\mu \mathrm{m}$ (Fig. 9 A), redondeados en sus extremos y con base trunca, solitarios, en pequeños grupos o lateralmente directamente en las hifas. El desarrolo conidial se describe como anelídico, una situación difícil de observar al microscopio. En el tiempo, un sinanamorfo en Graphium puede observarse frecuentemente en los extremos de las colonias, con conidióforos cilíndricos, café oliva, lisos, que termina en un racimo de células conidiógenas anelídicas delgadas, con conidios subhialinos 0 café pálidos reunidos en substancia mucoide, ampliamente clavados, 6-12 x 3,5-4 $\mu \mathrm{m}$ (B). Distribución universal. Temperatura óptima de crecimiento, 30-37C.Vea Tabla 2.

Los miembros del clado S.apiospermum, son morfológicamente indistinguibles del anamorfo de Pseudallescheria boydii, y taxas asociados, pero pueden separarse por la respuesta del test de la D-ribosa y por la ausencia de teleomorfo (Tabla2).

Debido a que el teleomorfo no se observa en los aislados de $\boldsymbol{S}$. apiospermum, se aparearon un buen número de aislados en todas las posibles combinaciones. Varias de éstas producen ascomata fértiles típicos del género Pseudallescheria, mientras todos los aislados solos fueron autoestériles. Se pudo agrupar los aislados en dos tipos diferentes de cruzanmiento: los cruzamientos entre la progenie de ascosporas F1, demonstró un sitema de apareamientoa bi-alélico heterotálico. Vea Gilgado et al., 2010.

\section{Pseudallescheria minutispora Gilgado,Gené, Cano \& Guarro Anamorfo Scedosporium sp., Graphium sp.}
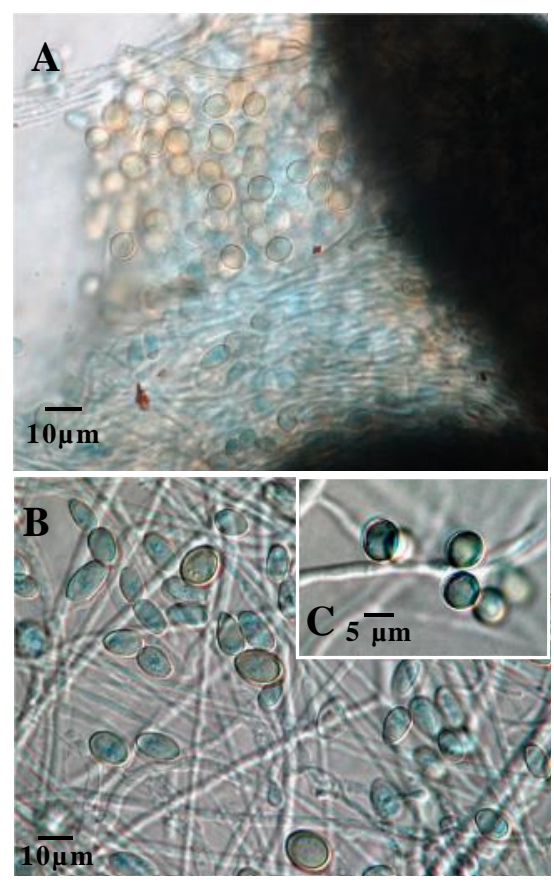

Figura 8. A-B-C, Pseudallescheria boydii. A. Clestotecio con ascosporas, B. Conidios del anamorfo desde células conidiógenas anelídicas, $C$. conidios sésiles desde hifas vegetativas.
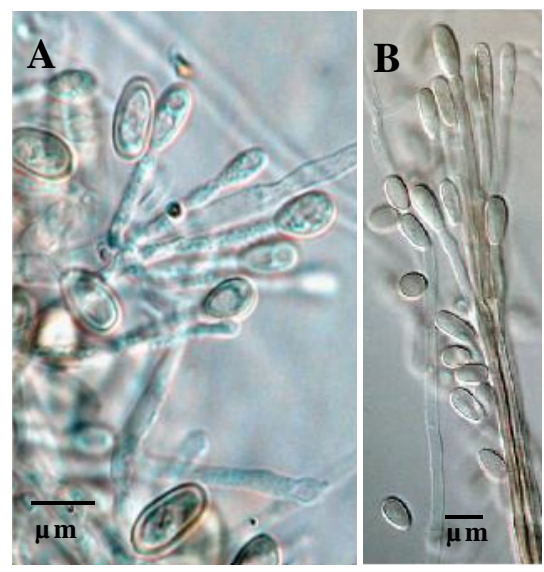

Figura 9. A-B, Scedosporium apiospermum, A. Conidios desde células conidiógenas anelídicas, B. Graphium sp.sinanamorfo, células conidiógenas conidios y sinema. 
El complejo Pseudallescheria/Scedosporium y taxas afines en la rutina del laboratorio micológico clínico - E.Piontelli.

Colonias de crecimiento relativamente rápido $(50-57 \mathrm{~mm}$ a los 14 días en PDA a $25^{\circ} \mathrm{C}$, algodonosas a lanosas, gris naranja a combinado con áreas gris café; ascomata abundantes en agar avena 50-150 $\mu \mathrm{m}$ diám., (Homotálico).perido de textura epidermoidea, gris amarillento a cafesoso-gris, recubierto a veces por hifas café de paredes gruesas. Ascos (8 esporas) esféricos a subesféricos, 12-15 x10-13 $\mu \mathrm{m}$, evanescentes, ascosporas unicelulares, con un poro germinal en ambos extremos, elipsoides, 5-7×3-4 $\mu \mathrm{m}(\mathbf{A})$, usualmente con una gota de acéite.

Scedosporium obovoidales, elipsoidales a subclaviformes 6$11 \times 3-4 \mu \mathrm{m}$ (B), lisos, subhialinos sobre conidióforos escasamente ramificados. Conidios de Graphium, cilíndricos a claviformes, de base trunca, 5-14 x 2-4,5 $\mu \mathrm{m}$, sobre sinnemata erecto de 180-300 $\mu \mathrm{m}$ de largo Conidios en hifas vegetativas escasos, elipsoidales 0 obovoides $7-10 \mathrm{x}$ 3,5-5 $\mu$ m.usualmente sésiles, subhialinos,lisos de paredes gruesas. Temperatura óptima 25 a $30^{\circ} \mathrm{C}$, crecimiento máximo $40^{\circ} \mathrm{C}$, pero puede crecer hasta $42^{\circ} \mathrm{C}$. Distribución Bélgica, España.(Gilgado et al., 2005).

4. Pseudallescheria fusoidea (Arx)McGinnis, A.A.Padhye \& Ajello (= Petrellidium fusoideum).Anamorfo Scedosporium sp., Graphium sp.

Colonias de crecimiento moderadamente rápido en 14 días en PDA a $^{-} 25^{\circ} \mathrm{C}, 69-70 \mathrm{~mm}$; grises a café pálido. Ascomata 50-160 $\mu \mathrm{m}$ diám. Ascos abovados a esféricos 12-15 x 10-12 um. Ascosporas ampliamente fusiformes, atenuadas en ambos extremos por poros germinales, 6-7,5 (-9) $\times$ 4-4,5 $\mu \mathrm{m}$ (Fig. 11. A). Conidios de Scedosporium, 6-7 (-9) x 2,54,5 $\mu \mathrm{m}$ (B); conidios en hifas vegetativas abundantes, esféricos a subesféricos, 4-7x 4-5 $\mu \mathrm{m}$. Sinanamorfo en Graphium raramente presente,con conidios de 4-7 x 4-5 $\mu \mathrm{m}$.

Filogenéticamente $\boldsymbol{P}$. fusoidea y $\boldsymbol{P}$. angusta son especies muy relacionadas, sin embargo, $\boldsymbol{P}$. angusta muestra ascomata pequeños (hasta $110 \mu \mathrm{m}$ en diám,) y ascosporas angostas (3 - $3.5 \mu \mathrm{m}$ de ancho versus 4-4,6 $\mu \mathrm{m}$ en $\boldsymbol{P}$. fusoidea); además las colonias de $\boldsymbol{P}$. angusta son más pequeñas (52 a $54 \mathrm{~mm}$ en 14 días en PDA a $25^{\circ} \mathrm{C}$ ).Vea: Von Arx et al., 1988; Gilgado et al., 2005; Guarro et al., 2012.

\section{Scedosporium aurantiacum Gilgado, Cano, Gené, et Guarro.}

Colonias en PDA , 40 a $50 \mathrm{~mm}$ después de 14 días a $25^{\circ} \mathrm{C}$, algodonosas o lanosas especialmente en el centro, frecuentemente con anillos con-céntricos de micelio aéreo de diferentes colores, amarillo-gris con áreas grises a cafesosas, reverso cafe naranja al centro. Todos los aislados producen un pigmento difusible amarillo claro en PDA o agar avena después de unos pocos días de incubación. Conidióforos solitarios en el micelio aéreo 0 en grupos formando sinnemata (Graphium) frecuentemente en la superficie del agar. Conidióforos a menudo reducidos a células conidiógenas que crecen lateralmente en un micelio indiferenciado 0 ramificado, usualmente presentando verticilios de 2-3 células conidiógenas. Se observan 3 tipos de conidios. a) los producidos en conidióforos solitarios, subhialinos, de paredes lisas obovoides 0 subcilíndrico, 5 -14 ×2 - $5 \mu$ m (Fig. 12); (b) Los producidos en sinnemata, predominantemente cilíndricos 0 claviformes, $6-12 \times 3-5 \mu \mathrm{m}$ con una amplia base trunca,(c) los que se producen en hifas indiferenciadas, sésiles, solitarios, laterales, café, lisos y de paredes gruesas usualmente obovoides, $6-10 \times 3-5 \mu \mathrm{m}$. Estos últimos se producen abundantemente en todos los aislados. Teleomorfo desconocido. Optima temperatura 37$40^{\circ} \mathrm{C}$. Máxima temperatur a $45^{\circ} \mathrm{C}$. No crece a $50^{\circ} \mathrm{C}$. (Vea Gilgado et al., 2005)

6. Complejo Scedosporium dehoogii Gilgado, Cano, Gené et Guarro, Clado 3 sensu Gilgado et al. (2008). Las colonias en PDA alcanzan un diámetro de 45 a $60 \mathrm{~mm}$ a $25^{\circ} \mathrm{C}$

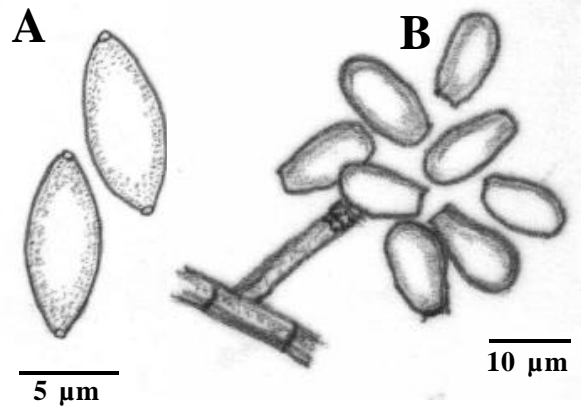

Figura10. A-B .Pseudoallescheria minutispora, A. Ascosporas con poro germinal en ambos extremos, B. Conidios del anamorfo.

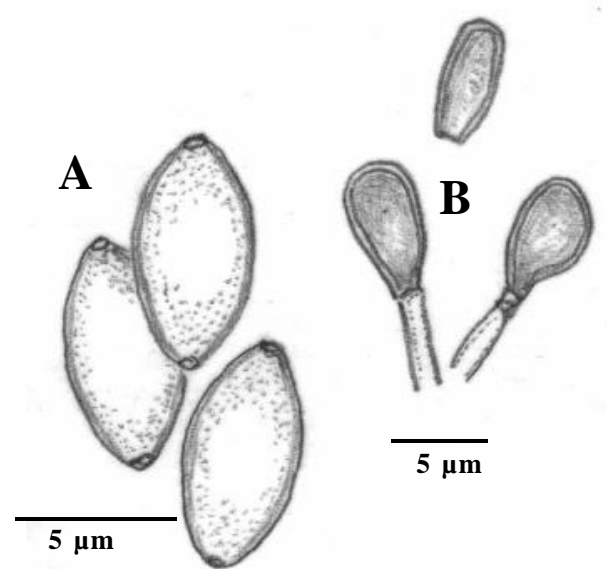

Figura11. A-B.Pseudoallescheria fusoidea, A. Ascosporas con poro germinal en ambos extremos, B. Conidios del anamorfo.

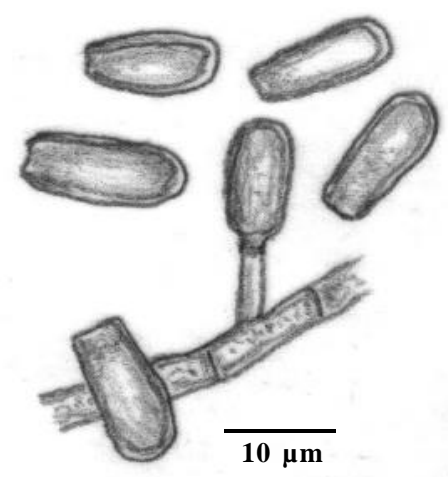

Figura 12. Scedosporium aurantiacum. Conidios en conidióforos solitarios. 
después de 14 días. Algodonosas, blancas a gris pálido con reverso incoloro; conidióforos solitarios son usualmente reducidos a células conidiógenas, subhialinas, de paredes lisas. usualmente cilíndricas $6-50 \times 1-1,5 \mu \mathrm{m}$, que producen conidios café pálidos, obovoides 0 elipsoidales, 6 - 11 x $4-5 \mu \mathrm{m}$. Conidióforos sinematosos erectos, 80-450 $\mu$ m de largo, que terminan en una cabeza mucosa de conidios. Conidios cilíndricos o claviformes, $6-11 \times 3-4$ $\mu \mathrm{m}$ (Fig. 13 B), de base trunca. Conidios sésiles subhialinos a gris pálido, de paredes delgadas, mayormente abovados, $5-8 \times 5-6 \mu \mathrm{m}$ (A). No se observa teleomorfo en ninguno de los aislados después de 2 meses de cultivo. Máximo crecimiento a $37^{\circ} \mathrm{C}$ (5 a $10 \mathrm{~mm}$ en diám. en 14 días). El hongo puede asimilar ribitol, L-arabinitol, sucrosa y maltosa, pero no D-ribosa (Tabla 2).Gilgado et al., 2008)

Este hongo es común en el ambiente, sin ambargo un número reducido de casos se han reportado en la literatura. Agunas cepas de $\boldsymbol{S}$. dehoogii difieren de la especie tipo en las secuencias de ITS. Estas cepas se agrupan en 2 clados en las secuencias de ITS, así como en el gen de la b-tubulina (BT2). Las diferencias se encontraron también en los rangos de crecimiento en agar polivinil alcohol agar suplementado con diesel, aceite de semilla de colza 0 sin suplemento, en la apariencia de las colonias en los medios que contienen aceite y su crecimiento a $41^{\circ} \mathrm{C}$ en PDA. En base a esto se propuso una nueva especie Scedosporium deficiens. Vea Rainer \& Kaltseis (2010).

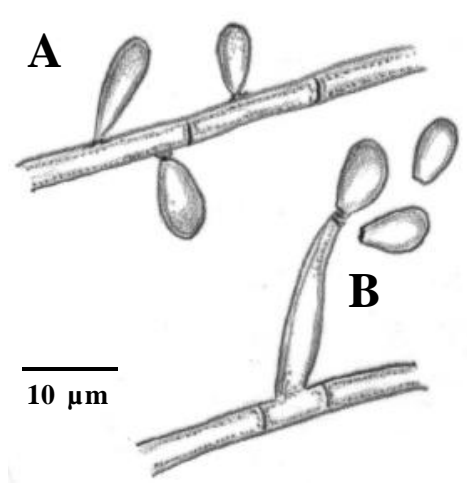

Figura13. A-B, Scedosporium dehoogii. A Conidios sésiles, B. conidios sobre células conidiógenas anelídicas

7. Scedosporium prolificans (Hennebert \& B.G. Desai) E. Guého \& de Hoog (=Scedosporium.inflatum, = Lomentospora prolificans). Teleomorfo desconocido.

Las colonias de $\boldsymbol{S}$. prolificans crecen rápidamente a $25^{\circ} \mathrm{C}$ y maduran en 5 días en agar Sabouraud. Textura algodonosa y mucoide inicialmente, posteriormente se aplanan con presencia de mechones de micelio finos y cortos. En su anverso las colonias son de un color gris claro a negruzco y se tornan gris negro a negro en la madurez, con el reverso gris a negro (Fig.7, A-B). Presencia de hifas hialinas septadas y finas donde las células conidiógenas se producen en su extensión. Células conidiógenas en forma de frasco, de base inflada que se adelgazan hacia el ápice formando un largo cuello proliferante (anelídico). Conidios solitarios o en pequeños grupos en el ápice de las anélides, de paredes lisas, hialinos a café pálido, ovoides a piriformes, de base trunca, 2 - 5 × 3

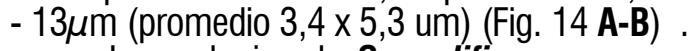

Las colonias de $\boldsymbol{S}$. prolificans son oscuras si se comparan con $\boldsymbol{S}$. apiospermum (Fig. 6) La células conidiógenas infladas (anélides) y sus conidios levemente anchos de S.prolificans, así como su inhabilidad de asimilar ribitol, xylitol, y L-arabinitol, permiten diferenciar las 2 especies. La diferenciación de ambas especies puede efectuarse también mediante PCR o pruebas de hibridización.(Weddle et al.,1998; De Hoog et al., 2000).
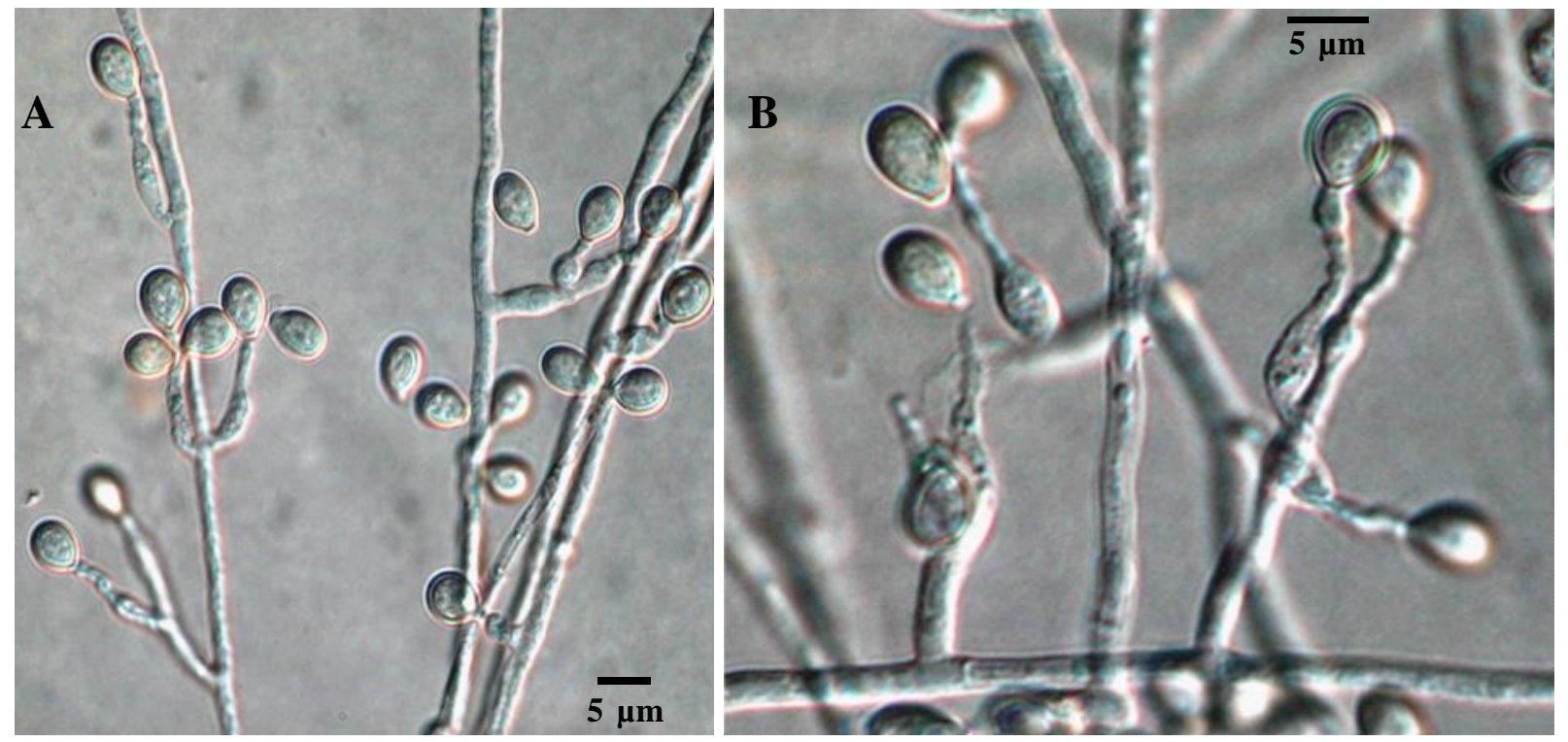

Figura 14. A-B. Scedosporium prolificans. Células conidiógenas anelídicas y conidios a diferentes aumentos. 
El complejo Pseudallescheria/Scedosporium y taxas afines en la rutina del laboratorio micológico clínico - E.Piontelli.

Tabla 1.- El complejo Pseudallescheria y taxa relacionados en las Microascales

(Adaptada de: Lackner et al., www.scedosporium-ecmm.com/.../Lackner2_3rd... 2010 y Lackner \& De Hoog, 2011)

\begin{tabular}{|c|c|c|c|}
\hline $\begin{array}{c}\text { Pseudallescheria } \\
\text { (Oportunista) }\end{array}$ & \begin{tabular}{|l} 
Teleomorfo \\
Pseudallescheria boydii \\
Pseudallescheria apiosperma \\
Pseudallescheria minutispora \\
Pseudallescheria desertorum \\
------
\end{tabular} & $\begin{array}{l}\text { Anamorfo } \\
\text { Scedosporium boydii } \\
\text { Scedosporium apiospermum } \\
\text { Scedosporium sp. } \\
\text { Scedosporium sp } \\
\text { Scedosporium aurantiacum } \\
\text { Scedosporium dehoogii } \\
\text { Scedosporium deficiens }\end{array}$ & $\begin{array}{l}\text { Sinanamorfo } \\
\text { Graphium sp. } \\
\text { Graphium sp. } \\
\text { Graphium sp. } \\
------ \\
----\end{array}$ \\
\hline $\begin{array}{l}\text { Parascedosporium } \\
\text { (Sin tendencia) }\end{array}$ & Parascedosporium putredinis* & Semejante a scedosporium & Graphium sp. \\
\hline $\begin{array}{l}\text { Sc. prolificans } \\
\text { (Oportunista) }\end{array}$ & & Scedosporium prolificans & ----------- \\
\hline $\begin{array}{l}\text { Petriellopsis } \\
\text { (Suelo y excrementos) }\end{array}$ & Petriellopsis africana & Scedosporium sp. & Graphium sp. \\
\hline $\begin{array}{l}\text { Petriella } \\
\text { (Suelo, excrementos) }\end{array}$ & $\mid \begin{array}{l}\text { Petriella guttulata } \\
\text { Petriella setifera } \\
\text { Petriella sordida }\end{array}$ & $\begin{array}{l}\text { Scedosporium sp. } \\
\text { Scedosporium sp. } \\
\text { Scedosporium sp. } \\
\text { Scedosporium lesnei }\end{array}$ & Graphium sp \\
\hline $\begin{array}{l}\text { Graphium } \\
\text { ( Escarabajos de } \\
\text { la corteza) }\end{array}$ & $\begin{array}{l}\text { Graphium basitruncatum } \\
\text { Graphium penicillioides } \\
\text { Graphium laricis** } \\
\text { Graphium pseudomictrum } * * \\
\text { Graphium fimbrisporum }\end{array}$ & 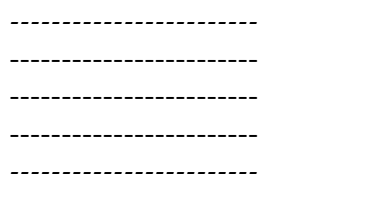 & ------------ \\
\hline $\begin{array}{l}\text { Lophotrichus } \\
\text { Parapetriella }\end{array}$ & $\begin{array}{l}\text { |Lophotrichus fimetii } \\
\text { |Parapetriella lindforsii }\end{array}$ & $\begin{array}{l}\text { Scedosporium sp. } \\
\text { Scedosporium sp. }\end{array}$ & ------------ \\
\hline
\end{tabular}

* (Incluye: Graphium laricis, Graphium putredinis, Parascedosporium tectonae, Rhinocladium lesnei. Lackner \& De Hoog, 2011) ** Graphium laricis y G dormiticum son morfológicamente y molecularmente casi idénticos, pero con distintos ambientes ecológicos (Okada et al., 1998; Kirschner, 1998)

\section{Tabla 2. Diferenciación morfofisiológica entre especies del complejo Pseudallescheria/Sce- dosporium y $S$. prolificans en PDA a $2^{\circ} \mathrm{C}$ en 14 días (Gilgado et al., 2008)}

\begin{tabular}{|c|c|c|c|c|c|c|c|c|c|c|c|}
\hline Especie & $\begin{array}{c}\text { Célula } \\
\text { conidiógena }\end{array}$ & $\begin{array}{cr}\text { Conidio } & \mathrm{Re} \\
\text { sésiles } & \mathrm{co} \\
& \text { tono a }\end{array}$ & $\begin{array}{l}\text { verso } \\
\text { lonia } \\
\text { marillo }\end{array}$ & $\begin{array}{l}\text { Pigmento } \\
\text { difusible } \\
0\end{array}$ & Rib. & L-Arab. & Sucr. & Malt. & D-Rib & $40^{\circ} \mathrm{C}$ & $45^{\circ} \mathrm{C}$ \\
\hline $\begin{array}{l}\boldsymbol{P} \text {. boydii y } \\
\text { relativos* }\end{array}$ & $\begin{array}{ll}\text { Cilìndrica } & \mathrm{C} \\
& \mathrm{p}\end{array}$ & $\begin{array}{l}\text { Glob- subglob. } \\
\text { pared gruesa }\end{array}$ & - & $\mathrm{V}$ & + & + & + & + & + & + & - \\
\hline P. minutispora & Cilìndrica $\begin{array}{r}\mathrm{E} \\
\mathrm{pa}\end{array}$ & $\begin{array}{l}\text { Elips-obovoide } \\
\text { ared-delgada }\end{array}$ & - & - & + & + & + & - & - & + & - \\
\hline S.apiospermum & $n$ Cilíndrica $\quad$ & $\begin{array}{l}\text { Glob-subglob. } \\
\text { ared gruesa }\end{array}$ & - & V & + & + & + & + & - & + & - \\
\hline S. aurantiacum & a Cilìndrica o & Obovoide & & & & & & & & & \\
\hline complex & $\begin{array}{l}\text { ligeramente } \\
\text { forma de frasco }\end{array}$ & Pared gruesa & + & + & + & + & - & + & + & + & + \\
\hline $\begin{array}{l}\text { S. dehoogii } \\
\\
\\
\text { for }\end{array}$ & $\begin{array}{l}\text { Cilíndrica o } \\
\text { ligeramente } \\
\text { ma de frasco }\end{array}$ & $\begin{array}{l}\text { Obovoide } \\
\text { pared delgada }\end{array}$ & - & - & + & + & + & + & - & - & - \\
\hline S. prolificans $\mathrm{F}$ & orma de frasco & $\begin{array}{l}\text { Glob-subglob. } \\
\text { pared gruesa }\end{array}$ & - & - & - & - & - & + & - & + & $\mathrm{V}$ \\
\hline
\end{tabular}


El complejo Pseudallescheria/Scedosporium y taxas afines en la rutina del laboratorio micológico clínico - E.Piontelli.

Abreviaciones y símbolos. * P.angusta. P. ellipsoidea y $\boldsymbol{P}$. fusoidea. Estas especies pueden clasificarse por medios molculares 0 mediante características morfológicas. Abreviaciones Rib. $=$ Ribosa, L.arab. $=$ L-Arabinosa, Sucr. $=$ Sucrosa, Malt. $=$ Maltosa, D. Rib. $=$ D-Ribosa.. El signo V corresponde a variable. El signo (-) respuesta negativa y el signo (+) respuesta positiva.

\section{REFERENCIAS}

Ajello, L.(1952). The isolation of Allescheria boydii Shear, an etiologic agent of mycetomas from soil. J. Trop. Med. 1:27-238

Alastruey-Izquierdo, A.; Cuenca-Estrella, M. \& Monzon, A. et al., (2007). Prevalence and susceptibility testing of new species of Pseudallescheria and Scedosporium in a collection of clinical mold isolates. Antimicrob. Agents. Chemother. 51:748-51

Arx, J.A.von. (1973). The genus Petrellidium and Pithoascus (Microascaceae) Persoonia 8:367-375

Arx, J.A. von.; Guarro, J. \& Figueras, M.J. (1988). Sordaria-ceous ascomycetes without ascospore ejaculations. Nova Hedwigia Beih. 84:1-103

Bakerspigel A, Schaus, D. (1984). Petriellidiosis (pseudallescheriasis) in southwestern Ontario, Canada. Sabouraudia 22:247249

Bonduel, M.; Santos, P.; Turienzos, C.F.; Chantada, G, Paga-nini H. (2001). Atypical skin lesions caused by Curvularia sp. and Pseudallescheria boydii in two patients after allogenic bone morrow transplantation. Bone Marrow Transplant. 27:1311-1313

Blyth, C.C.; Harun, A.; Middleton, P.G. et al. (2010).Detection of occult Scedosporium species in respiratory tract specimens from patients with cystic fibrosis by use of selective media. J. Clin. Microbiol. 48:314-6

Briones, E et al., (2006). Neumonia grave por Scedosporium apiospermum en paciente con síndrome de Goodpasture. Soc, Chil. de Nefrología. Congreso 2006 Valdivia. Libro Resumenes pág. 18

Castellani, A. \& Chalmers, A.J. (1919). Manual of tropical medicine.Williams, Wood, and Co.,New York.

Chanqueo, L. et al., (2009). Infección rinosinusal por Scedosporium apiospermum en un hospedero inmunocompetente. Rev. Chil. Infect.26 (5): 453-456

Clauben, S. \& Schmidt, S. (1999). Biodegradation of phenylbenzoate and some of its derivatives by Scedosporium apiospermum Research in Mycobiology 150:413-420

Cruywagen, E.M.; de Beer, Z.W.; Roux,J. \& Wingfield, M.J. (2010). Three new Graphium species from baobab trees in South Africa and Madagascar. Peersoonia 25:61-71

Cooke, W.B. \& Kahler, P.G. (1955). Isolation of potentially pathogenic fungi from polluted water and sewage. Publ. Health. Rep. 170:689-694
Cortez, K.J et al., (2008). Infections Caused by Scedosporium spp. Clin.Micobiol. Rev. 21:157-197

Dabrowa, N.; Landau, J.W.; Newcomer, V.D. \& Plunkett, O.A. (1964). A survey of tidewashed coastal areas of Southern California for fungi potentially pathogenic to man. Mycopathologia 24:136-150

Dalton, P.; Munckhof, W. \& Walters DW. (2006). Scedosporium prolificans: an uncommon causeof septic arthritis. ANZ J. Surg. 76:661-663

Defontaine, A.; Zouhair, R.; Cimon B, et al., (2002). Genotyping study of Scedosporium apiospermum isolates from patients with cysticfibrosis. J. Clin. Microbiol. 40:2108

De Hoog, G.S.; Marvin-Sikkema, F.D.; Lahpoor GA, et al . (1994). Ecology and physiology of the emerging opportunistic fungi Pseudallescheria boydii and Scedosporium prolificans. Mycoses 37:71-78

De Hoog, G.S.; Guarro, J.; Gené, J.; Figueras, M.J. (2000). Atlas of clinical fungi, 2nd edn. Centraalbureau voor Schimmelcultures / Universitat Rovira i Virgili, Utrecht, The Netherlands / Reus, Spain.

De Hoog, G.S. (2012). ECMM-ISHAM Working Group on Pseudallescheria/Scedosporium infections (Internet).

De Hoog, G.S et al., (2011). Making Moulds Meet. Information retrieval as a basis for understanding Pseudallescheria and Scedosporium. Mycoses 54 (suppl. 3):1-4

Delhaes, L.; Harun, A.; Chen, S.C.A, et al., (2008). Molecular typing of Australian Scedosporium isolates showing genetic variability and numerous $\boldsymbol{S}$. aurantiacum. Emerg. Infec.Dis. 14: $282-290$

Díaz, M.C, et al., (2004). Absceso de herida operatoria por Scedosporium prolificans: Primer aislamiento en Chile. Revisión de la literatura. Rev. Chil. Infectología 21:65-69 Dykstra, M.J.; Salkin, I.F. \& McGinnis, M.R.(1989). An ultrastructural comparison of conidiogenesis in Scedosporium apiospermum, Scedosporium inflatum and Scopulariopsis brumptii. Mycologia 81:896-904

Eggertsberger, M.; Rainer, J.; Kaltseis,J.; Pöder, P. \& de Hoog, G.S. (2010). Temperature dependence and environmental conditions enhancing the distribution of the opportunistic pathogens Pseudallescheria and Scedosporium. (www.scedosporium-ecmm.com/.../Eggertsberger) 
El complejo Pseudallescheria/Scedosporium y taxas afines en la rutina del laboratorio micológico clínico - E.Piontelli.

Emmons, C.W. (1944). Allescheria boydii and Monosporium apiospermum. Mycologia 36:188-193

Fessler, R.G.. \& Brown, F.D. (1989). Superior sagittal sinus infection with Petriellidium boydii: case report. Neurosurgery 24: $604-607$

Gelabert-González, M. et al. (2010). Absceso cerebral por Scedosporium apiospermum. Presentación de un caso con revisión de la literatura. Neurocirugía 21:125-131

Gilgado F, Cano J, Gene J, Guarro J. (2005).Molecular phylogeny of the Pseudallescheria boydii species complex: proposal of two newspecies. J. Clin. Microbiol. 43:4930-4942 Gilgado, F.; Serena, C.; Cano, J.; Gené, J.; Guarro J. (2006). Antifungal susceptibilities of the species of the Pseudallescheria boydii complex. Antimicrob. Agents Chemother. 50:4211-4213

Gilgado, F.; Cano, J.; Gene, J.; Sutton, D.A.; Guarro J. (2008). Molecular and phenotypic data supporting distinct species statuses for Scedosporium apiospermum and Pseudallescheria boydii and the proposed new species Scedosporium dehoogii. J. Clin. Microbiol. 46:766-771

Gilgado,F.; Gené,J.; Cano,J. \& Guarro,J. (2010). Heterothallism in Scedosporium apiospermum and description of its teleo-morph Pseudallescheria apiosperma sp.nov.Med.Mycol.48:122-128

Guarro, J, et al. (2006) Scedosporium apiospermum: changing clinical spectrum of a therapy-refractory opportunist. Med. Mycol. 44:295-327

Guarro, J.; Gené, J.; Stchigel, A.M. \& Figueras, J. (2012). Atlas of soil Ascomycetes. CBS Biodiversity Series 10, Utrecht, Netherlands

Gueho, E \& de Hoog, G,S. (1991). Taxonomy of the the medical species of Pseudallescheria and Scedosporium. J. Mycol. Méd.118:3-9

Kantarcioglua, A.S.; de Hoog, G.S. \& Guarro. J. (2012). Clinical characteristics and epidemiology of pulmonary pseudallescheriasis. Rev Iberom. Micol. 29:1-13

Harun, A.; Gilgado, F.; Chen, S. \& Meyer, W. (2009a). Environmental isolation of Scedosporium species from the greater Sydney region a link to the emergence of infections in Australia?. Microbiology Australia May:98-101

Harun, A.; Perdomo, H.; Gilgado, F.; Chen, S.; Cano, J.; Guarro, J, Meyer W. (2009b).Genotyping of Scedosporium species: a review of molecular approaches. Medical Mycology 2009, 47:406-414

Horre,R. et al., (2011). Physiological typing of Pseudallescheria and Scedosporium strains using Taxa Profile, a semi-automated, 384-well microtitre system. Mycoses 54(Suppl.3):56-65

Hughes, SJ. (1958). Revisiones hyphomycetum aliquot cum appendice de nominilus rejiciendisi. Can. J. Bot. 36:727-836

Issakainen, J.; Jalava, J.; Eerola, E. \& Campbell, C.K. (1997). Relatedness of Pseudallescheria, Scedosporium and Graphium pro parte based on SSU rDNA sequences. J. Med. Vet. Mycol. 35: 389-398

Issakainen, J.; Jalava, J.; Saari, J. \& Campbell, C.K. (1999). Relationship of Scedosporium prolificans with Petriella confirmed by partial LSU rDNA sequences. Mycological Research 103: 1179-1184

Kaltseis, J. et al. (2009) Ecology of Pseudodallescheria and Scedosporium species in human-dominated and natural environments and their distribution in clinical samples. Med. Mycol. doi: 10.1080/13693780802585317

Kirk, P.W. (1967). A comparison of saline tolerance and sporulation in marine and clinical isolates of Allescheria boydii Shear. Mycopathol. Mycol. Appl. 1967; 33: 6575

Kirschner, R. (1998). Diversität mit Borkenkäfern assoziierter fila-mentöser Mikropilze. PhD thesis, Biologische Fakultät. Eberhard-Karls -Universität Tübingen, Germany.

Krasny, L. et al., (2011). Scedosporium and Pseudallescheria low molecular weight metabolites revealed by database search. Mycoses 54 (Suppl.3):37- 42

Kumar, D.; Sigler, L.; Gibas, C.F.; Mohan, S.; Schuh, A. et al.,(2007). Graphium basitruncatum fungemia in a patient with acute leukemia. Journal of Clinical Microbiology 45:1644-1647

Lackner, M.A.H.G.;Gerrits van den Ende.;Kaltseis, J. \& de Hoog, G.S. (2010): Taxonomy, barcoding and diagnostics of therapy refractory Pseudallescheria and Scedosporium species. Scedosporium Meeting (www.scedosporiumecmm.com/.../Lackner2_3rd...

Lackner, M. et al., (2011a). Rapid Identification of Pseudallescheria and Scedosporium Strains by Using Rolling Circle Amplification Applied and Environmental Microbiology 78:126133

Lackner M. et al., (2011b). Infection and colonisation due to Scedosporium in Northern Spain. An in vitro antifungal susceptibility and molecular epidemiology study of 60 isolates. Mycoses 54 (Suppl. 3):12-21

Lackner, M. \& de Hoog, G.S. (2011). Parascedosporium and its relatives: phylogeny and ecological trends. IMA Fungus 2:39-48

Lackner, M.; Klaassen, C.H.; Meis, J.F.; van den Ende, A.H.; de Hoog, G.S. (2012).Molecular identification tools for sibling 
El complejo Pseudallescheria/Scedosporium y taxas afines en la rutina del laboratorio micológico clínico - E.Piontelli.

species of Scedosporium and Pseudallescheria. Med Mycol. 50:497-508

Lu, Q. et al., (2011).Identification of Pseudallescheria and Scedos-porium Species by Three Molecular Methods. J. Clin Microbiol 49:960-967

Malloch, D. (1970). New concepts in the Microascaceae illustrated by two new species.Mycologia 62:727-739

Malloch, D. \& Salkin, I.A. (1984). A new species of Scedosporium associated with osteomyelitis in humans. Mycotaxon 21: $247-255$

Oddo, D.; Lobos, T.; González, A. \& Fardella, C. (1985). Pseudoallescheriasis pulmonar no invasiva. Un caso con diagnóstico histopatológico y micológico en material obtenido por broncoscopia. Rev. Méd. Chil. 1985:113:999-1003

Okada, G.; Seifert, K.A.; Takematsu, A.; Yamaoka, Y.; Miyazaki, S.; Tubaki, K. (1998) A molecular phylogenetic reappraisal of the Graphium complex based on 18S rDNA sequences. Canadian Journal of Botany 76:1495-1506

Okada, G.; Jacobs, K.; Kirisits, T.; Louis-Seize, G.W, Seifert, K.A.; Sugita, T.; Takematsu, A.; Wingfield, M.J. (2000). Epitypification of Graphium penicillioides Corda, with comments on the phylogeny and taxonomy of Graphium-like synnematous fungi. Studies in Mycology 45:169-188

Perdomo, Z. (2011). Cracterización fenotípica y molecular de hongos filamentosos oportunistas: Scedosporium, Acremonium, Phialemonium, Lecythophora y Paecilomyces. Tesis Doctoral, Universitat Rovira i Virgili, Departament de Ciències Mèdiques Bàsiques. Reus, España.

Rainer, J. \& de Hoog, G.S. (2006). Molecular taxonomy and ecology of Pseudallescheria, Petriella and Scedosporium prolificans (Microascaceae) containing opportunistic agents on human. Mycological Res. 110:151-160

Rainer,J.; Kaltseis, J.; de Hoog,S.G. \& Summerbell, R. (2008). Efficacy of a selective isolation procedure for members of the Pseudallescheria boydii complex. Antonie van Leeuwenhoek 93:315-322

Rainer, J. \& Kaltseis, J. (2010). Diversity in Scedosporium dehoogii (Microascaceae): $\boldsymbol{S}$. deficiens sp. nov. Sydowia 62:137-147

Rodriguez-Tudela, J.L. et al. (2009). Epidemiology and outcome of Scedosporium prolificans infection, a review of 162 cases. Med. Mycol. 47:359-370

Ruiz-Diez, B.: Martin-Diez, F;; Rodriguez-Tudela, J.L, Alvarez, M.; Martinez-Suarez, J.V. (1997). Use of random amplification of polymorphic DNA (RAPD) and PCR fingerprinting for genotyping of a Scedosporium prolificans (inflatum) outbreak in four leukaemic patients. Curr. Microbiol. 35:186-190

San Millan, R.; Quindos, G.; Garaizar, J. et al., (1997). Characterization of Scedosporium prolificans clinical isolates by randomly amplified polymorphic DNA analysis. J. Clin. Microbiol. 35:2270-2274

Shear, C.L. (1922). Life history of an undescribed ascomycete isolated from a granular mycetoma of man. Mycologia 14:239243

Sitterle, E. et al., (2012). Utilisation du MALDI-TOF-MS pour l'identification rapide et precise des especes cliniques de Scedospo-rium et de Pseudallescheria. Medical Mycology 22:100-101

Sole, M.; Cano, J.; Rodriguez-Tudela, L. et al. (2003). Molecular typing of clinical and environmental isolates of Scedosporium prolificans by inter-simple-sequence-repeat polymerase chain reaction. Med. Mycol. 41:293-300

Steinmann, J.; Schmidt, D.; Buer, J. \& Rath, P.M. (2011). Discrimination of Scedosporium prolificans against Pseudallescheria boydii and Scedosporium apiospermum by semiauto-mated repetitive sequence-based PCR. Med. Mycol. 49:475-83

Ulfig-J,K.; Ulfig, K.; Cano, J. \& Guarro, J. (2008). A study of the growth of Pseudallescheria boydii isolates from sewage sludge and clinical sources on tributyrin, rapeseed oil, biodiesel oil and diesel oil. Ann. Agric. Environ. Med. 15:45-49

Vuillemin, P. (1910). Description d'un type de chaque ordre de Conidiosporés. Bulletin des Séances du Société des Sciences de Nancy, Sér. 3, 11:138-143

Zeng, J.S.; Fukushima, K.; Takizawa, K. et al., (2007). Intraspecific diversity of species of Pseudallescheria boydii complex. Med. Mycol. 45:547-558

Zouhair, R.; Defontaine, A.; Ollivier, C. et al., (2001). Typing of Scedosporium apiospermum by multilocus enzyme electrophoresis and random amplification of polymorphic DNA. J. Med. Microbiol. 50:925-932

Walts, A.E. (2001). Pseudallescheria: an underdiagnosed fungus? Diagn. Cytopathol. 25:153-157

Wedde, M.; Muller, T.; Tintelnot, K. De Hoog, G.S.; U. Stahl. (1998). PCR-based identification of clinically relevant Pseudallescheria/Scedosporium strains. Med. Mycol. 36:6167

Williamson, E.; Speers, D.; Arthur, I.H. et al., (2001). Molecular epidemiology of Scedosporium apiospermum infection determined by PCR amplification of ribosomal intergenic spacer sequences in patients with chronic lung disease. J. Clin. Microbiol. $39: 47-50$ 